\title{
GAMBARAN TINGKAT PENGETAHUAN DAN SIKAP PELAJAR TENTANG PENYALAHGUNAAN NAPZA DI SMP KRISTEN ATAMBUA KABUPATEN BELU NUSA TENGGARA TIMUR
}

\author{
Billy Wilsen Senduk*) \\ Yusfina Modesta Rua*) \\ Maria Fatimah W.A Fouk*)
}

*)Prodi Keperawatan Universitas Timor Kampus Atambua, Jl. Wehor Kabuna Haliwen Atambua, Nusa Tenggara Timur. Post 85711. Email: sendukwilsen666@gmail.com. Phone: 082144203072

\begin{abstract}
ABSTRAK
Penelitian ini dilaksanakan di SMP Kristen Atambua, Kabupaten Belu, Nusa Tenggara Timur dari tanggal 13 Januari - 21 Januari 2019. Penyalahgunaan NAPZA melahirkan masalah sosial, keamanan, dan ketertiban dimasyarakat seperti tindakan kriminal, prostitusi, disharmoni keluarga, peningkatan jumlah pengangguran, dan peningkatan jumlah putus sekolah. Tujuan dari penelitian ini adalah untuk mengidentifikasi gambaran tingkat pengetahuan dan sikap pelajar di SMP Kristen Atambua tentang penyalahgunaan NAPZA. Populasi adalah siswa/i kelas VII, VIII dan IX SMP Kristen Atambua, sampel sebanyak 165 responden yang memenuhi kriteria inklusi. Teknik pengambilan dengan stratifed random sampling, analisa data mencakup analisa univariat. Hasil penelitian yang di peroleh berdasarkan pengetahuan didapatkan responden yang pengetahuannya kurang sebanyak $84,2 \% \quad(n=139)$ dan responden yang pengetahuannya baik sebanyak $0,6 \%(n=1)$. Ini berarti sebagian besar responden tidak mengetahui pengertian istilah NAPZA, jenis NAPZA, dampak penggunaan NAPZA, serta bentuk NAPZA yang kemungkinan dipengaruhi oleh beberapa faktor yaitu faktor pendidikan, informasi, dan usia. Sedangkan berdasarkan sikap didapatkan responden yang mempunyai sikap cukup terhadap penyalahgunaan NAPZA adalah $51,5 \%(\mathrm{n}=85)$ dan responden yang mempunyai sikap baik terhadap penyalahgunaan NAPZA adalah 48,5\% $(n=80)$ hal ini berarti sebagian besar responden belum bisa mengambil sikap yang benar atas pengetahuan yang ia ketahui mengenai NAPZA.
\end{abstract}

Kata Kunci: NAPZA, Pengetahuan, Sikap 


\title{
DESCRIPTION OF THE LEVEL OF KNOWLEDGE AND ATTITUDES OF STUDENTS REGARDING DRUG SBUDE IN ATAMBUA CHRISTIAN MIDDLE SCHOOL BELU DISTRICT, EAST NUSA TENGGARA
}

\author{
Billy Wilsen Senduk*) \\ Yusfina Modesta Rua*) \\ Maria Fatimah W.A Fouk*)
}

\begin{abstract}
*)Nursing Program at University of Timor, Atambua Campus, Jl. Wehor Kabuna Haliwen Atambua, East Nusa Tenggara. Post 85711. Email: sendukwilsen666@ gmail.com. Phone: 082144203072
\end{abstract}

\begin{abstract}
This research was conducted at Atambua Christian Middle School, Belu Regency, East Nusa Tenggara from January 13 to January 21, 2019. Drug abuse creates social, security and order problems in the community such as crime, prostitution, family disharmony, an increase in unemployment, and an increase in the number of dropouts. The purpose of this study was to identify the description of the level of knowledge and attitudes of students at Atambua Christian Middle School about drug abuse. The population is students of class VII, VIII and IX at Atambua Christian Middle School, a sample of 165 respondents who met the criteria for taking techniques with stratifed random sampling, data analysis included univariate analysis. The results of the research obtained based on knowledge were obtained by respondents whose knowledge was less are $84.2 \%$ $(n=139)$ and respondents with good knowledge are $0.6 \%(n=1)$. This means that the majority of respondents did not know the meaning of drugs, drug types, the impact of drug use, and forms of drugs that might be influenced by several factors, namely the education factor, information, and age. Whereas based on attitudes, respondents who have sufficient attitudes towards drug abuse are $51.5 \%(\mathrm{n}=85)$ and respondents who have good attitudes towards drug abuse are $48.5 \%(\mathrm{n}=80)$, this means that most respondents cannot take an attitude that true of the knowledge he knew about drugs.
\end{abstract}

Keywords: Drug, Knowledge, Attitude. 


\section{PENDAHULUAN}

Gaya hidup masyarakat dewasa ini menimbulkan banyak masalah yang mengancam berbagai aspek kehidupan masyarakat terutama pada generasi muda. Salah satunya yaitu ketergantungan pada Narkotika, Alkohol, Psikotropika, dan Zat Adiktif lainya (NAPZA). Aspek kejadian penyalahgunaan NAPZA cenderung terus meningkat dari tahun ke tahun. Remaja adalah generasi muda yang masih memiliki jiwa dan tingkat emosional yang belum stabil, rasa ingin tahu yang tinggi, mudah terpengaruh hal-hal negatif, solidaritas berlebihan, keinginan eksis dalam pergaulan, serta lebih cepat berinteraksi dengan berbagai lingkungan masyarakat, sehingga rentan terhadap penyalahgunaan NAPZA (Putri, 2017). Penyalahgunaan narkotika dewasa ini telah mencapai situasi yang mengkhawatirkan sehingga menjadi masalah nasional maupun internasional yang mendesak. Indonesia saat ini bukan hanya merupakan daerah transit tetapi sudah menjadi daerah pemasaran. Kasus-kasus narkotika saat ini sangat mengejutkan karena korbannya sebagian besar generasi muda yang masih sangat produktif sehingga ancaman rusaknya generasi penerus bangsa ada di depan mata (Setiyawati, et all. 2015).

\section{World Drug Report dari United} Nations Office on Drugs and Crime (UNODC) melaporkan secara global bahwa pada tahun 2011 ada 167-315 juta orang dengan rentang usia 15-64 tahun aktif mengonsumsi NAPZA dan pada tahun 2012 menyatakan bahwa sekitar 230 juta penduduk dunia merupakan pengguna narkoba dan 27 juta orang diantaranya adalah pecandu narkoba (Putri, 2017). Prevalensi penyalahgunaan NAPZA di Indonesia terus meningkat setiap tahun. Menurut hasil survei Badan Narkotika Nasional (BNN) yang bekerjasama dengan Pusat Penelitian Kesehatan Universitas Indonesia (UI), prevalensi penyalahgunaan NAPZA di Indonesia pada kelompok usia 10-59 tahun 2009 adalah 1,99\% atau sekitar 3,6 juta jiwa lalu meningkat menjadi $2,2 \%$ atau sekitar 3,8 juta jiwa pada tahun 2011. Selain itu, pada tahun 2016 diperoleh angka prevalensi penyalahguna narkoba pada kelompok pelajar dan mahasiswa sebesar 1,9\% atau dengan kata lain 2 dari 100 orang pelajar dan mahasiswa menyalahgunakan narkoba. Sedangkan sampai dengan Maret 2017, BNN telah mengungkap 807 kasus narkotika dan mengamankan 1.238 tersangka serta mengidentifikasi 65 New Pshychoactive Substance (NPS) (Direktorat Diseminasi Informasi Deputi Bidang Pencegahan, 2017). Dari hasil survei Penyalahgunaan dan Peredaran Gelap Narkoba (P4GN) BNN Republik Indonesia pada tahun 2009 menyatakan bahwa rata-rata usia pertama kali menyalahgunakan NAPZA pada usia yang sangat muda yaitu 12-15 tahun. Angka penyalahgunaan NAPZA berdasarkan tingkat pendidikan SLTP/SMA tahun 2012 berjumlah 9.743 kasus. Fakta ini mengindikasikan bahwa peredaran gelap NAPZA masih tetap marak di kalangan pelajar Indonesia (Fadhilah et al., 2012).

BNNP Jabar melaporkan bahwa tahun 2011, Prevalensi penyalahgunaan NAPZA di Jawa Barat menempati peringkat ke-6 di Indonesia. Prevalensi penyalahgunaan narkotika di Jawa Barat mencapai $2,5 \%$ jumlah penduduk atau sekitar 1,1 juta jiwa dan $22 \%$ diantaranya adalah pelajar (Afianty, et all. 2014). Badan Narkotika Nasional Provinsi (BNNP) Nusa Tenggara Timur mencatat selama tahun 2017 terdapat 32.000 orang warga diwilayah provinsi berbasis kepulauan ini menjadi pengguna narkotika dan obat-obatan terlarang yang didominasi masyarakat dengan tingkat ekonomi mapan.

Dari hasil rekapitulasi kuesioner Badan Narkotika Nasional Kabupaten Belu dalam Kegiatan Diseminasi Informasi Melalui Media Konvensional Tatap Muka di sejumlah SMA dan SMA di Kabupaten Belu didapatkan hasil dari 6 SMA dan 7 SMA yang dilakukan penyuluhan tingkat pemahaman tentang penyalahgunaan narkoba masih tergolong kategori sedang dengan jumlah persentase sebesar $78 \%$ dari jumlah total 
keseluruhan (Data Sekunder BNN Kabupaten Belu, 2018).

$$
\text { Remaja }
$$

menjadi

target

penyalahgunaan NAPZA karena masa remaja adalah masa pencarian identitas diri, perasaan penasaran dan ingin mencoba hal baru yang sangat besar. Dapat dikatakan bahwa pada saat ini Indonesia sedang dilanda penyalahgunaan narkoba yang sangat serius karena mengancam generasi muda. Remaja merupakan golongan yang rentan terhadap penyalahgunaan narkotika karena selain memiliki sifat dinamis, energik, selalu ingin mencoba, mereka juga mudah tergoda dan mudah putus asa sehingga mudah jatuh pada masalah penyalahgunaan narkotika. Menurut faktor penyebab, tingginya pengguna narkoba dari usia muda karena sejumlah faktor, diantaranya, keinginan untuk coba-coba lantaran diajak teman, gaya hidup yang bebas dan pergaulan yang tidak baik (Setiyawati et al., 2015).

Permasalahan ini perlu mendapat perhatian dari pihak pemerintah serta instansi yang mempunyai tugas khusus dalam menyelesaikan serta memberikan solusi terhadap permasalahan dalam lingkungan pelajar sekarang ini. Jika pemerintah serta instansi yang berkaitan tidak memberikan perhatian khusus pada pelajar-pelajar berupa penyuluhan-penyuluhan tentang pengetahuan dan pemahaman tentang bahaya narkoba, baik secara langsung ataupun melalui media sosial hal ini yang menjadi penyebab utama pelajar menggunakan istilah "coba-coba" disebabkan karena minimnya pengetahuan tentang narkoba, termasuk di kota Atambua.

Siswa SMA merupakan salah satu kelompok remaja yang rawan terkena dampak penyalahgunaan NAPZA. Mereka memiliki sifat rasa ingin tahu yang tinggi dan selalu ingin mencoba hal-hal yang baru sehingga rentan dan mudah terjebak oleh perilaku negatif dan menyimpang, termasuk salah satunya penyalahgunaan NAPZA. Sebagian besar remaja menggunakan narkoba karena motif ingin tahu, adanya kesempatan dan prasarana-sarana, ketidakstabilan emosi dan lemahnya mental. Selain itu, beberapa faktor lain yang mendukung tindakan penyalahgunaan narkoba ini antara lain gangguan psikososial keluarga, lemahnya pendidikan agama dan bimbingan konseling di sekolah, serta faktor pergaulan dan budaya global.

SMA Kristen Atambua sebagai salah satu sekolah menengah pertama yang terletak di tengah kota, hal ini memudahkan akses masuk informasi, narkoba, dan perkembangan gaya hidup dan pola pergaulan remaja sekarang ke sekolah ini sangatlah mudah. Akibatnya, beberapa perilaku dan tindakan siswa sudah mulai mengarah ke perilaku menyimpang, salah satu contohnya yaitu merokok dan minum-minuman keras. Berdasarkan hasil observasi dan wawancara peneliti dengan para siswa, terdapat beberapa orang siswa yang merokok. Nikotin pada rokok merupakan salah satu bahan adiktif. Banyak penyalahgunaan NAPZA berawal dari merokok (Nufajri et al., 2013). Berdasarkan hasil wawancara dengan Kepala SMA Kristen Atambua, di jelaskan bahwa hampir setiap tahun ada siswa yang kedapatan merokok dilingkungan sekolah maupun diluar sekolah. Upaya preventif terhadap penyalahgunaan narkoba melalui penyuluhan sudah pernah diadakan di sekolah ini, tetapi pengukuran sejauh mana tingkat pengetahuan dan sikap siswa siswi belum pernah dilakukan.

Berdasarkan uraian di atas, maka peneliti tertarik untuk melakukan penelitian tentang "Hubungan Tingkat Pengetahuan dan Sikap Pelajar Tentang Penyalahgunaan NAPZA di SMA Kristen Atambua Kabupaten Belu Nusa Tenggara Timur".

\section{METODOLOGO}

Penelitian ini dilakukan kepada siswa/i kelas VII,VIII, dan IX SMP Kristen Atambua. Penelitian dilaksanakan pada bulan Januari 2019. Adapun total populasi dalam penelitian ini adalah 258 siswa/i. Teknik sampling yang digunakan yaitu teknik stratifed random sampling.

Metode yang digunakan dalam penelitian ini adalah metode deskriptif dengan menggunakan pendekatan kuantitatif yang bertujuan untuk mengekspresikan Gambaran Tingkat Pengetahuann dan Sikap Pelajar Tentang Penyalahgunaan NAPZA di SMP 
Kristen Atambua Kbupaten Belu Nusa Tenggara Timur.

Teknik analisa data yang digunakan dalam penelitian ini adalah dengan menggunakan Univariat yaitu menganalisa terhadap tiap variabel dari hasil tiap penelitian untuk menghasilkan distribusi frekuensi dan presentase dari tiap variabel.

\section{HASIL PENELITIAN}

Tabel 1.

Distribusi Frekuensi Responden Berdasarkan Usia di SMP Kristen Atambua Januari 2019

$$
(n=165)
$$

\begin{tabular}{llll}
\hline Variabel & Kategori & Frekuensi & Presentasi \\
\hline Usia & $10-13$ & 84 & 50,9 \\
& $14-16$ & 77 & 46,6 \\
& $17-20$ & 4 & 2,4 \\
\hline & & 165 & 100
\end{tabular}

Sumber : Data primer, 2019

Berdasarkan tabel di atas didapatkan sebagian besar responden berusia 10-13 tahun sebanyak 50,9 \% $\quad(n=84)$, sedangkan sebagian kecil berusia 17-20 tahun sebanyak 2,4\% $(n=4)$.

Tabel 2.

Distribusi Frekuensi Responden

BerdasarkanJenis Kelamin di SMP Kristen

Atambua, Januari $2019(n=165)$

\begin{tabular}{lll}
\hline Jenis Kelamin & Frekuensi & Persentase \\
\hline Laki-laki & 95 & 57,6 \\
Perempuan & 70 & 42,4 \\
Total & 165 & 100 \\
\hline Sumber : Data pring
\end{tabular}

Sumber : Data primer, 2019

Berdasarkan tabel di atas didapatkan sebagian besar responden berjenis kelamin laki-laki sebanyak 57,6 \% $(\mathrm{n}=95)$, sedangkan sebagian kecil berjenis kelamin perempuan sebanyak 42,4 \% $(n=70)$.

Tabel 5.

Distribusi Frekuensi Pengetahuan Responden Tentang Penyalahgunaan NAPZA di SMP Kristen Atambua, Januari $2019(n=165)$

\begin{tabular}{llll}
\hline Variabel & Kategori & Frekwensi & $\begin{array}{l}\text { Presentase } \\
(\boldsymbol{\%})\end{array}$ \\
\hline \multirow{3}{*}{ Pengetahuan } & Baik & 1 & 0,6 \\
& Cukup & 25 & 15,2 \\
& Kurang & 139 & 84,2 \\
\hline Total & & 165 & 100 \\
\hline
\end{tabular}

Sumber: Data primer, 2019

Berdasarkan tabel di atas didapatkan hasil sebagian besar tingkat pengetahuan responden tentang penyalahgunaan Napza kurang, yaitu sebanyak 84,2 \% (n=139), sedangkan sebagian kecil responden dengan tingkat pengetahuan baik sebanyak $0,6 \%$ $(\mathrm{n}=1)$.

Tabel 6.

Distribusi Frekuensi Sikap Responden Tentang Penyalahgunaan NAPZA di SMP Kristen Atambua, Januari $2019(n=165)$

\begin{tabular}{llll}
\hline Variabel & Kategori & Frekuensi & $\begin{array}{l}\text { Presentase } \\
(\boldsymbol{\%})\end{array}$ \\
\hline \multirow{2}{*}{ Sikap } & Baik & 80 & 48,5 \\
& Cukup & 85 & 51,5 \\
Total & Kurang & 0 & 0,0 \\
\hline Sumber & & 165 & 100 \\
\hline
\end{tabular}

Sumber : Data primer, 2019

Berdasarkan tabel di atas didapatkan hasil sebagian besar sikap responden tentang penyalahgunaan Napza termasuk kategori cukup sebanyak $51,5 \% \quad(n=85)$, sedangkan sebagian kecil sikap responden dalam kategori baik sebanyak 48,5\% $(n=80)$.

\section{PEMBAHASAN}

\section{a. Karakteristik Responden di SMP Krsiten Atambua}


Siswa/i dalam penelitian ini sebagian besar berusia 13 dan 14 tahun dengan jumlah hampir sama yaitu 55 orang $(33,3 \%)$ dan 42 orang $(25,4 \%)$. Usia remaja 13 tahun masuk dalam usia remaja awal (early adolescence) usia 11-13 tahun. Seorang remaja pada tahap ini masih heran akan perubahan-perubahan yang terjadi pada tubuhnya. Remaja mengembangkan pikiran-pikiran baru, cepat tertarik pada lawan jenis, dan mudah terangsang secara erotis. Pada tahap ini remaja awal sulit untuk mengerti dan dimengerti oleh orang dewasa. Remaja ingin bebas dan mulai berfikir abstrak (Sarwono, 2011).

Hasil penelitian menunjukkan bahwa jenis kelamin responden sebagian besar lakilaki yaitu 95 orang $(57,5 \%)$. Hasil penelitian Musmarf (2017) menyatakan bahwa remaja laki-laki lebih tinggi intensitas kenakalannya dibandingkan perempuan, laki-laki lebih mungkin menyalahgunakan NAPZA dibanding dengan perempuan. Hasil Penelitian Maharti (2015) menyatakan bahwa beberapa kasus narkoba yang melibatkan anak kebanyakan yang berisiko adalah anak lakilaki, karena pada umumnya anak laki-laki usia 14-16 tahun sudah mulai merokok, dan rokok tersebut merupakan pintu awal anak untuk masuk dalam jurang narkoba.

\section{b. Tingkat Pengetahuan Tentang Penyalahgunaan Napza}

Berdasarkan hasil analisis univariat didapatkan bahwa dari 165 responden, sebagian besar mempunyai tingkat pengetahuan kurang sebanyak 84,2 \% $(\mathrm{n}=139)$ tentang penyalahgunaan NAPZA, ditemukan pula sebanyak $0,6 \% \quad(n=1)$ memiliki tingkat pengetahuan baik, dan untuk tingkat pengetahuan cukup sebanyak 15,2\% $(n=25)$.

Hasil Penelitian ini sesuai dengan hasil penelitian sebelumnya yang dilakukan oleh Yuyun (2015) dari Sekolah Tinggi Ilmu Kesehatan Hang Tuah Pekanbaru yaitu dari 178 responden yang diteliti di Marpoyan Indah didapatkan sebagian besar responden mempunyai pengetahuan yang masih kurang $(58 \%)$. Selain itu, hasil studi pendahuluan Fadillah, et all (2012) terhadap siswa kelas VII SMP Negeri Se-Kecamatan Johar Baru dengan cara penyebaran angket, didapatkan masih banyak siswa yang tidak memahami apa NAPZA, apa saja jenisnya dan bagaimana dampak dari penyalahgunaan NAPZA. Penelitian lainnya yang dilakukan oleh Puspaini pada tahun 2017 terhadap pelajar di SMK Negeri 01 Dumai mendapatkan hasil bahwa responden yang pengetahuannya sedang $(23,5 \%)$ dan rendah $(8,1 \%)$ atau dapat dikatakan pengetahuannya kurang terhadap Penyalahgunaan NAPZA.

Hal ini sesuai dengan teori yang dikemukakan oleh Notoatmodjo, 2012 dalam Zaen (2017) bahwa pengetahuan adalah hasil penginderaan manusia atau hasil tahu seseorang terhadap objek melalui indera yang dimilikinya. Dengan sendirinya pada waktu penginderaan menghasilkan pengetahuan tersebut, dan sangat dipengaruhi oleh intensitas perhatian dan persepsi terhadap ojek. Pengetahuan seseorang bisa diperoleh dari pengalaman yang berasal dari berbagai macam sumber, seperti media massa, media elektronik, buku petunjuk, petugas kesehatan, media poster, kerabat dekat, dan sebagainya. Sumber-sumber tersebut didapatkan melalui penginderaan khususnya melalui mata dan telinga. Seseorang dengan sumber informasi yang banyak dan beragam akan menjadikan orang tersebut memiliki pengetahuan yang luas. Faktor yang dapat mempengaruhi pengetahuan banyak perubahan secara kognitif, emosional dan sosial, seshingga mereka berfikir lebih kompleks. Pada tahap perkembangan ini remaja mempunyai rasa ingin tahu yang sangat besar sehingga akan mencari tahu informasi dan berperilaku sesuai informasi yang didapatkan (Wawan dan Dewi, 2010 dalam Zaen (2017). Kurangnya pengetahuan merupakan salah satu penyebab terjadinya penyalahgunaan NAPZA, karena remaja masih mempunyai pengetahuan yang terbatas dan pengetahuan yang tidak tepat dan benar (berpikiran abstrak) tentang bahaya NAPZA (Wong, 2003 dalam Puspaini (2017)

Berdasarkan Fakta dan Teori di atas dapat dijelaskan bahwa tingkat pengetahuan responden di SMP Kristen Atambua masih kurang. Pengetahuan yang kurang ini kemungkinan dipengaruhi oleh beberapa faktor : 1). Faktor pendidikan, dimana semakin tinggi pendidikan seseorang 
umumnya memiliki pengetahuan yang lebih baik. 2). Faktor Informasi, informasi yang didapatkan oleh remaja sekarang ini kebanyakan dari media sosial sehingga remaja tidak memiliki konsep yang jelas tentang penyalahgunaan NAPZA. 3). Faktor Usia, usia rata-rata responden di SMP Kristen Atambua masuk dalam kategori remaja awal dimana remaja pada tahap ini masih heran akan perubahan-perubahan yang terjadi pada tubuhnya. Remaja ingin bebas dan mulai berfikir abstrak.

\section{c. Sikap Pelajar Tentang Penyalahgunaan Napza}

Berdasarkan hasil analisis univariat didapatkan bahwa dari 165 responden, yang mempunyai sikap cukup terhadap penyalahgunaan NAPZA sebanyak $51,5 \%$ $(\mathrm{n}=85)$, dan yang mempunyai sikap baik terhadap penyalahgunaan NAPZA sebanyak $48,5 \%(\mathrm{n}=80)$.

Hasil penelitian ini sesuai dengan hasil penelitian yang dilakukan oleh Paruliyan $\mathrm{R}$ (2011) dari Universitas Pembangunan Nasional Veteran Jakarta pada remaja yang ditahan di Polres Metro Jakarta Selatan menunjukkan bahwa mayoritas responden, yaitu sebanyak 32 responden (64\%) memiliki sikap kurang. Selain itu, hasil penelitian yang dilakukan oleh Puspaini (2017) dari Akademi Keperawatan Sri Bunga Tanjung didapatkan sebagian besar $58,1 \% \quad(n=79)$ mempunyai sikap positif terhadap penyalahgunaan NAPZA atau dapat dikatakan mempunyai sikap yang baik. Sedangkan $42,9 \% \quad(n=57)$ mempunyai sikap negatif atau cukup terhadap penyalahgunaan NAPZA

Hal ini sesuai dengan teori yang dikemukakan oleh Notoatmodjo, 2007 dalam Zaen (2017) bahwa sikap adalah suatu bentuk evaluasi atau reaksi perasaan. Sikap seseorang terhadap suatu objek adalah perasaan mendukung atau memihak (favourable) maupun perasaan tidak mendukung atau tidak memihak (unfavourable) pada objek tersebut. Sikap dapat dipengaruhi oleh beberapa faktor diantaranya faktor internal dan eksternal. Faktor internal meliputi jenis kelamin, umur, pendidikan dan pengalaman. Faktor eksternal meiputi media massa, institusi pendidikan, institusi agama dan masyarakat. Kepribadian remaja pada masa ini timbul unsur baru yaitu kesadaran akan kepribadian dan kehidupan badaniah sendiri. Remaja mulai menentukan nilai-nilai tertentu dan melakukan penentuan sikap terhadap pemikiran filosofi dan etis. Selain itu pada masa ini remaja menemukan diri sendiri atau jati dirinya. Sikap merupakan reaksi tertutup bukan merupakan rekasi yang terbuka. Sikap merupakan kesiapan untuk bereaksi terhadap objek di lingkungan tertentu sebagai suatu penghayatan terhadap objek. Sikap adalah kecenderungan individu untuk berekasi terhadap suatu obyek, mendekati atau menjauh. Sebagai contoh apabila kita sudah mengetahui bahwa narkoba itu tidak baik untuk kesehatan, maka hendaknya kita menjahui segala sesuatu yang berhubungan dengan narkoba tersebut (Nawar,2002).

Berdasarkan Fakta dan Teori di atas dapat dijelaskan bahwa sikap responden di SMP Kristen Atambua paling banyak kategori cukup. Hal ini kemungkinan disebabkan oleh beberapa faktor antara lain : Kecenderungan selalu ingin tahu akan membentuk sikap dan perilaku menjauhi narkoba, namun semakin remaja mencari informasi maka remaja semakin memiliki kecenderungan untuk memakai narkoba dan peraturan yang kurang ketat dan kurang disiplin dari pihak sekolah dapat mempengaruhi sikap pelajar tersebut.

\section{KESIMPULAN DAN SARAN}

Dari hasil penelitian yang dilakukan peneliti pada tanggal 13 Januari sampai 21 Januari 2019 di SMP Kristen Atambua dengan judul penelitian "Gambaran Tingkat Pengetahuan dan Sikap Pelajar Tentang Penyalahgunaan NAPZA di SMP Kristen Atambua Kebupaten Belu Nusa Tenggara Timur", peneliti mengambil kesimpulan sebagai berikut:

1. Tingkat pengetahuan pelajar tentang penyalahgunaan NAPZA adalah kurang $(84,2 \%)$.

2. Sikap pelajar tentang penyalahgunaan NAPZA adalah cukup $(51,5 \%)$.

\section{Saran}


Berdasarkan kesimpulan di atas maka peneliti menyarankan kepada beberapa pihak sebagai berikut :

1. Untuk Pelajar SMP Kristen Atambua

Disarankan untuk banyak belajar tentang pengertian narkoba, jenis-jenisnya, penyebab serta dampak dari penyalahgunaan NAPZA.

2. Untuk Institusi

Diharapkan dapat menyediakan referensi yang terbaru mengenai hal-hal yang berkaitan dengan pengetahuan dan sikap tentang penyalahgunaan NAPZA dan diharapkan pula dapat berpartisipasi serta berperan aktif dalam kegiatan sosialisasi khususnya tentang pentingnya pendidikan kesehatan tentang penyalahgunaan NAPZA juga tidak lepas dari tanggung jawab petugas kesehatan.

3. Untuk SMP Kristen Atambua

Disarankan untuk mendatangkan tenaga kesehatan atau dari BNN (Badan Narkotika Nasional) sebagai bentuk preventif berupa penyuluhan atau sosialisasi di awal tahun pembelajaran baru. Serta sebagai tambahan bahan pertimbangan dalam upaya penanggulangan penyalahgunaan NAPZA bagi remaja.

4. Untuk Masyarakat

Disarankan kepada masyarakat dalam hal ini keluarga untuk dapat memperhatikan perkembangan anaknya yang masih berusia remaja karena sangat diperlukan peran serta orang tua dalam tahap perkembangan anak usia remaja ini.

5. Untuk Peneliti Selanjutnya

Hasil penelitian ini diharapkan dapat menambah pengetahuan wawasan peneliti tentang tingkat pengetahuan dan sikap pelajar tentang penyalahgunaan NAPZA. Sekaligus sebagai bahan masukan atau sumber data untuk peneliti selanjutnya dengan menambah penelitian tentang perilaku karena memiliki hubungan yang kuat terhadap pengetahuan dan sikap pelajar dan mendorong pihak yang berkepentingan untuk melakukan penelitian lebih lanjut.

\section{KEPUSTAKAAN}

Afianty, Raisa Dewi, et all. 2014. Gambaran Pengetahuan, sikap dan Perilaku Siswa-siswi Sekolah Menengah Kejuruan " $X$ " tentang NAPZA di Kota Bandung Tahun 2014. Fakultas Kedokteran Universitas Maranatha: Bandung.

Anwar, Herson. 2009. Penilaian Sikap Ilmiah Dalam Pembelajaran Sains. Jurnal Pelangi Ilmu Volume 2 No 5.

Anisa Dwi Putri, 2017. Pengetahuan Dan Sikap Pelajar SMA Negeri 17 Makassar Tentang Penyalahgunaan NAPZA ( Narkotika, Psikotripika, Dan Zat Adiktif). Fakultas Kedokteran Universitas Hasanuddin: Makassar

Anggoro, Aji. 2014. Suatu Tinjauan Tentang Sikap Remaja Dalam Penyalahgunaan NARKOTIKA Dan Obat Terlarang Dikelurahan Sidodadi Kecamatan Samarinda Ulu Samarinda. Fakultas Ilmu Sosial dan Ilmu Politik Universitas Mulawarman: Samarinda.

Amiruddin et al., 2013. Gambaran Pengetahuan Dan Sikap Remaja Tentang NAPZA Di SMA Negeri 1 Bungoro Kabupaten Pangkep. STIKES Nani Hasanuddin Makassar: Makassar.

Bakhtiar, Amsal. 2011.Filsafat Ilmu. Jakarta : Rajawali Pers.

Fadillah Nubaiti et al., 2012. Hubungan Pemahaman NAPZA Dengan Sikap Terhadap Penyalahgunaan NAPZA (Studi Korelasi Pada Siswa Kelas VIII SMP Negeri Se-Kecamatan Johar Baru).FIP UNJ.

Jaji. 2009. Hubungan Faktor Sosial dan Spiritual Dengan RisikoPenyalahgunaan NAPZA Pada Remaja SMP dan SMA di Kota 
Palembang. $\quad$ PSIK-FK UNSRI:

Palembang.

Jewana, Satya dan Lydia Harlina M. 2006. Pencegahan Dan Penanggulangan Penyalahgunaan NARKOBA Berbasis Sekolah. Jakarta : Balai Pustaka.

Kumurur, Veronica A. 2008. Pengetahuan, Sikap dan Kepedulian Mahasiswa Pascasarjana Ilmu Lingkungan Terhadap Lingkungan Hidup Kota Jakarta. Fakultas Teknik Universitas Sam Ratulangi Manado: Manado.

Maharti, Vikiat Ika. 2015. Faktor-faktor yang Berhubungan dengan Perilaku Penyalahgunaan Narkoba pada Remaja Uia 15-19 Tahun Di Kecamatan Semarang Utara Kota Semarang. Fakultas Kesehatan Masyarakat Universitas Diponegoro: Semarang.

Nawar, Agus. 2002. Psikologi Pelayanan. Bandung : ALFABETA.

Nurfajri et al., 2013. Pengetahuan Dan Sikap Tentang Narkoba Pada Siswa-Siswi SMA Handayani Pekanbaru Sebelum Dan Sesudah Penyuluhan. Fakultas Kedokteran Universitas Riau: Riau.

Nur'artavia, Maydiya Restacendi. 2017. Karakteristik Pelajar Penyalahguna NAPZA dan Jenis NAPZA yang Digunakan di Kota Surabaya. Departemen Epidemiologi Fakultas Kesehatan Masyarakat Universitas Airlangga : Suarabaya.

Nurmaya, Alya. 2016. Penyalahgunaan NAPZA DiKalangan Remaja (Studi Kasus Pada 2 Siswa Di MAN 2 Kota Bima).STKIP Bima : Bima.

Puspaini, Ririn. 2017. Gambaran Pengetahuan Dan Sikap Remaja
Tentang Pencegahan Penyalahgunaan NAPZA Di Sekolah Menengah Kejuruan Negeri 01 Dumai. Akademi Keperawatan Sri Bunga Tanjung : Dumai.

Putri, Aidina et al., 2017. Hubungan Jenis Kelamin, Pengetahuan, Sikap, Lingkungan Keluarga Dan Teman Sebaya Terhadap Penyalahgunaan NAPZA Pada Siswa SLTA. Fakultas Kedokteran Universitas Lambung Mangkurat Banjarbaru : Bajarmasin.

Ratnasari, Yesi. 2015. Hubungan Pengetahuan, Sikap Siswa Tentang Bahaya Narkoba Dan Peran Keluarga Terhadap Upaya Pencegahan Narkoba (Studi Penelitian di SMP Agus Salim Semarang). Fakultas Kesehatan Marsyarakat Universitas Muhammadiyah Semarang Semarang.

Riduwan. 2012. Skala Pengukuran VariabelVariabel Penelitian. Bandung : ALFABETA.

Setiyawati, dkk. 2015. Buku Seri Bahaya Narkoba Penyalahgunaan Narkoba. Surakarta : PT Tirta Asih Jaya.

Siregar, Syofian. 2014. Metode Penelitian Kuantitatif Dilengkapi Dengan Perbandingan Perhitungan Manual \& SPSS. Jakarta : Kencana Prenadamedia Group.

Undang-Undang Republik Indonesia No. 35 Tahun 2009 Tentang Narkotika UUD RI Tahun 2009.

Willis, Sofyan S. 2010. REMAJA DAN MASALAHNYA Mengupas Berbagai Kenakalan Remaja Seperti Narkoba, Free Sex Dan Pemecahannya. Bandung : ALFABETA. 